\title{
O TEMPO COMO CRITÉRIO DE VERIFICAÇÃO DA POSSIBILIDADE DO DISCURSO FILOSÓFICO
}

\author{
Estevão Lemos Cruz ${ }^{1}$
}

\begin{abstract}
Resumo: O objetivo principal do presente estudo é identificar o tempo como o critério de verificação da possibilidade de um discurso filosófico, isto é, de uma possibilidade discursiva ser capaz de falar adequadamente acerca das palavras fundamentais. Para tanto, interessará mostrar como o tempo é o elemento vinculador das condiçôes de possibilidade do enunciado em geral e como este se fundamenta na estrutura imprópria da temporalidade. Tal prerrogativa é o que inviabiliza o enunciado tratar adequadamente qualquer palavra fundamental. Caberá, entâo, afirmar que somente uma possibilidade discursiva que se fundamente na estrutura própria da temporalidade poderá ter um acesso adequado às palavras fundamentais.
\end{abstract}

Palavras-chave: Heidegger. Tempo. Predicação. Discurso filosófico.

\section{INTRODUÇÃo}

A obra de um filósofo, em razão de sua natureza prolífica, tende a deixar para trás várias "pontas soltas" a se pensar. São conjecturas e pensamentos que, embora altamente interessantes, não constituem a meta da investigação do filósofo, quando da escrita do texto e, como tais, acabam sendo negligenciadas. Nosso estudo se ocupará de uma dessas "pontas soltas", no pensamento de Martin Heidegger, a saber, a análise do fundamento temporal de todo enunciado em geral.

Por "enunciado" ou "predicação" queremos dizer toda estrutura predicativa que se deixa reduzir à forma "S é P", seja no modo de uma afirmação, seja de negação. Mas como podemos evidenciar um fundamento temporal em tal estrutura? Embora Heidegger não tenha feito uma análise detida da temporalidade enquanto fundamento de todo enunciado em geral,

\footnotetext{
${ }^{1}$ Universidade Estadual do Paraná, Uniāo da Vitória, PR - Brasil. (DD orcid.org/0000-0002-4726-2118 E-mail: estevaolemoscruz@yahoo.com.br.
}

http://doi.org/10.1590/0101-3173.2020.v43n3.11.p167 
ele nos fornece todos os subsídios para tal. Contudo, onde está a "ponta solta” deixada por Heidegger que permite tal análise? Ela se encontra na preleção de inverno de 1925/26, intitulada Logik. Die Frage nach Der Wahrheit. Heidegger (1976, p. 194-195, tradução nossa) termina o $\$ 14$ com a seguinte frase:

A partir do esclarecimento da conexão interna de verdade [Wabrheit], desencobrimento enquanto presente [Entdecktheit als Gegenwart] e ser enquanto presentidade [Sein als Anwesenheit], surge só agora a necessidade de se fazer claro em que medida as três condiçōes de possibilidade da falsidade estâo conectadas entre si, para então mostrar que só há falsidade em geral na medida em que há temporalidade. ${ }^{2}$

A frase citada é bastante obscura, quando retirada de seu contexto. Quase não faz sentido por si só. À parte isso, a justificativa de que "só há falsidade em geral na medida em que há temporalidade" é bastante prejudicada no desenvolvimento da preleção de 1925/26, pois Heidegger se ocupará quase que exclusivamente da interpretação do problema do tempo na Crítica da Razão Pura e não apresentará uma explicação detalhada da frase citada. É nesse trecho pouco esclarecido que se encontra, portanto, nossa ponta solta. Como já ressaltamos, a frase é muito obscura, contudo, entrega várias informaçóes importantes: 1) há três condiçôes de possibilidade para a falsidade; 2) há algo que vincula tais condiçóes entre si e 3) só há falsidade na medida em que há temporalidade.

Mas o que queremos com tais afirmaçôes? O que a afirmação de que "só há falsidade em geral na medida em que há temporalidade" tem a ver com a afirmação de que há um fundamento temporal de todo enunciado em geral? Tais afirmaçóes se vinculam na medida em que as condiçóes de possibilidade da falsidade são as mesmas condiçôes de possibilidade de todo o enunciado em geral. ${ }^{3}$ Identificar a validade dessa afirmação é pressuposto necessário para alcançarmos o objetivo primeiro de nosso estudo, a saber, mostrar como $o$ tempo é o elemento vinculador das condiçóes de possibilidade do enunciado em geral. Uma vez alcançado tal objetivo, interessará evidenciar como o enunciado

\footnotetext{
${ }^{2}$ No original: "aus dem Einblick in diesen inneren Zusammenhang von Wabrheit, Entdecktheit als Gegenwart und Sein als Anwesenheit nun erst deutlich zu machen, inwiefern die drei Bedingungen der Möglichkeit der Falschheit sich zusammenhängen, um dann zu zeigen, daß es Falschheit iherhaupt nur gibt, sofern es Zeitlichkeit gibt".

${ }^{3} \mathrm{O}$ fato de as condições de possbilidade do enunciado serem as mesmas que da falsidade terá como consequência que todo enunciado será, de certa forma, encobridor. Note-se que o termo "falsidade", em Heidegger, carrega um sentido primário de "encobrimento", de "mostrar algo como aquilo que ele mesmo não é”, aspecto distinto da concepção tradicional de não-correspondência.
} 
se fundamenta na estrutura imprópria da temporalidade, isto é, na estrutura que fundamenta a compreensão vultar do tempo, o tempo do relógio. ${ }^{4}$

Se conseguirmos verificar que o enunciado encontra de fato seu fundamento na estrutura imprópria da temporalidade, teremos consequências interessantíssimas. Tal fundamento exigiria, por exemplo, que o enunciado necessariamente "coisifique"s o ente ao qual ele remete, o que tornaria essa possibilidade discursiva incapaz de tratar adequadamente qualquer palavra fundamental ${ }^{6}$ (ser, tempo, verdade, Deus, mundo, enfim), sem transformála em uma "coisa", sem "objetificá-la". Por sua vez, se é o modo como o enunciado se fundamenta na estrutura imprópria da temporalidade que o impede de tratar adequadamente tais palavras, entáo podemos argumentar que uma possibilidade discursiva que se fundamente na estrutura própria da temporalidade seria capaz de fazê-lo. Tal prerrogativa nos leva à novidade da investigaçáo proposta e que constitui nosso objetivo derradeiro, a saber, identificar o tempo como o critério genuino de verificação da possibilidade de um discurso falar propriamente acerca do ser e das demais palavras fundamentais. ${ }^{7}$

${ }^{4} \mathrm{Tal}$ estrutura baseia-se nas chamadas ekstases que Heidegger denominou Gewärtigen (expectação), Behalten (retenção) e Gegenwärtigen (presentificação) (HEIDEGGER, 2012a, p. 372ss; CRUZ, 2019b, p. 150 a 175).

${ }^{5}$ Se quisermos usar uma terminologia mais próxima ao vocabulário heideggeriano, diríamos que a estrutura imprópria da temporalidade que fundamenta o enunciado exige que o ente tratado pelo enunciado assuma o modo de ser de Vorhandenheit, o modo de ser dos entes simplesmente dados.

${ }^{6}$ Há, na filosofia heideggeriana, uma aproximação inevitável entre o que é filosofia e a investigação de palavras fundamentais. Tal aproximação é notória, nos próprios títulos dados às publicaçôes das preleçôes de Heidegger. Não é raro preleçôes ou obras do filósofo conterem no título expressôes como "Grundbegriffe" (conceito fundamental) (v.g. GA 18, 22, 29/30 e 51) ou, então, as próprias palavras fundamentais investigadas, como "ser" (GA 2, 36/37), "tempo" (GA2, 20, 64), "verdade" (GA 21 34, 36/37), "acontecimento" (GA 65, 71, 73), "pensamento" (GA 8, 13, 14, 73), "linguagem” (GA $12,38,7477,85)$, etc. Esse tipo de abordagem direta às palavras fundamentais é típica da filosofia de Heidegger e está presente em toda sua trajetória, quer em obras anteriores a Ser e Tempo, de 1927, quer em obras bastante tardias, como O que significa pensar? (GA 8), de 1951/52. É certo que o modo como Heidegger irá investigar as palavras fundamentais sofre alteraçóes significativas em sua trajetória, mas as palavras fundamentais nunca deixaram de ser o propósito último de seu pensar. Tal característica da filosofia heideggeriana faz com que a busca pelo acesso adequado a tais palavras seja também uma constante, no pensamento do filósofo. Nosso estudo colabora com a preocupação desse acesso adequado, na medida em que busca identificar um critério capaz de verificar se um determinado discurso tem a possibilidade ou não de oferecer acesso às palavras fundamentais.

${ }^{7}$ Por "critério de verificaçâo" concebemos um recurso capaz de identificar a diferença entre determinados elementos dados previamente. Por exemplo, o critério de verificação para determinar se uma solução é ácida ou alcalina é o seu $\mathrm{pH}$ (potencial Hidrogênico). Um pH abaixo de sete indica uma solução ácida, enquanto um pH acima de sete, uma solução alcalina. Perceba-se que, independentemente de ser ácida, alcalina ou neutra, toda solução apresenta um pH. Podemos nos referir de modo análogo a todo discurso em geral. A tese proposta em nosso estudo é de que todo modo discursivo em geral 
Uma vez informados nossos objetivos e a linha argumentativa que pretendemos seguir, cabe voltar à citação acima e entender como ela pode nos conduzir ao objetivo primeiro. Convém, no entanto, um esclarecimento do contexto que a antecipa.

No $\$ 13$ da "primeira parte principal” da preleção de 1925/26, em meio a uma interpretação do sentido aristotélico de verdade, Heidegger propôsse investigar as condiçóes de possibilidade para a falsidade do enunciado. As condições encontradas foram três:

1. A tendência para o descobrimento de algo - o prévio pensar e ter do "acerca-de-que". 2. Neste comportamento fundamental descobridor, enquanto que dominado e guiado por ele, um "deixar ver" do "acerca-deque" a partir de outro, pois apenas sobre o fundamento desta estrutura há a possibilidade do "fazer passar" algo enquanto algo. 3. Este "deixar ver" a partir de outro se fundamenta, ao mesmo tempo, na possibilidade da conjunção de algo com algo (HEIDEGGER, 1976, p. 187, traduçáo nossa).

Convém explicar um pouco melhor no que consistem tais condiçóes. A primeira delas - na qual as outras duas encontram sua base estrutural - é a própria tendência desveladora que o homem é e na qual os entes podem vir à tona. $\mathrm{O}$ traço fundamental que caracteriza o ente que eu mesmo sou (Dasein) é justamente o seu caráter de aberto, isto é, o fato de que ele compreende a si mesmo e aos outros entes, ao contrário, por exemplo, de um livro ou um lápis, que é incapaz de compreender ou perceber sua própria existência. $\mathrm{O}$ ente que eu mesmo sou (Dasein) distingue-se dos outros, por estar irremediavelmente lançado à tal compreensão, que é chamada por Heidegger de "compreensão de ser". Tal caráter de aberto é o "fazer ver" em geral que corresponde à própria abertura que o Dasein é e no qual se assentam todas as demais possibilidades de desvelamento. É a compreensão primária que já sempre abriu os entes de tal ou qual forma, de modo antepredicativo.

Se utilizarmos o vocabulário de Ser e Tempo, diríamos que a primeira condiçáo de possibilidade da falsidade nada mais é que o caráter de aberto

se fundamenta na temporalidade. Se esse fundamento for a temporalidade imprópria (o caso do enunciado), entâo tal modo discursivo necessariamente será "objetificante" e, consequentemente, não será apto para tratar acerca das palavras fundamentais. Se, contudo, o fundamento de determinado modo discursivo for a temporalidade própria, entâo tal modo não há de coisificar o que é tratado nele e pode possibilitar um acesso genuíno às palavras fundamentais. O modo como um determinado discurso se fundamenta na temporalidade é, portanto, o critério de verificação que permite identificar se tal discurso pode ou não tratar adequadamente das palavras fundamentais. 
(Erschlossenheit) do Dasein (HEIDEGGER, 2006, cap. 5). A segunda condição, por sua vez, firma-se na possibilidade de esse mesmo fazer ver primário ser um mostrar determinador, isto é, um mostrar algo enquanto algo a partir de algo outro. É necessário que aquilo que veio à tona seja compreendido e interpretado a partir de algo outro (HEIDEGGER, 2006, \$33). É isso que permite a estrutura predicativa "S é P". Quando enunciamos "o quadro é verde", já estamos nos movendo em uma determinação que toma o "quadro" a partir do "verde", isto é, a partir de algo outro. A terceira condição, por fim, diz respeito à possibilidade de o ente enunciado poder ser determinado, ou seja, carregar em seu modo de ser a possibilidade de sofrer uma conjunçáo, de mostrar-se junto com algo outro e, assim, possibilitar o mostrar determinador. Perceba-se que agora abordamos uma característica específica do ente e náo mais do fazer ver que o compreende e interpreta. Por exemplo, não basta me ser dada a mera possibilidade de determinar "a mesa é vermelha": é necessário que a mesa carregue em seu modo de ser a possibilidade de sofrer uma conjunçáo com a qualidade "vermelho", "plano", "metálico", enfim. A terceira condição aponta justamente para a possibilidade de o ente da predicação deixar-se mostrar por meio de qualidades, propriedades especificas.

Ora, mas o que a indicação das condiçóes de possibilidade da falsidade do enunciado tem a ver com os objetivos de nossa investigação? Como já mencionado, ocorre que tais condiçôes são elas mesmas não só condiçôes de possibilidade para a falsidade do enunciado, mas são também as condiçôes de possibilidade para todo enunciado em geral. Não há enunciado sem a 1) a précompreensão que abre algo previamente, de modo antepredicativo; 2) o mostrar que determina aquilo que foi dado na pré-compreensão, a partir de algo outro e, por fim, 3) a possibilidade de o ente poder mostrar-se junto com algo outro e, assim, possibilitar o mostrar determinador. Somente porque o enunciado se estrutura em tais condiçôes que ele pode assumir-se enquanto um mostrar determinador que deixa ver algo a partir de algo outro, isto é, "S é P". Se, conforme anunciamos, o objetivo primeiro de nosso estudo é demonstrar que o tempo é o elemento vinculador das condiçóes de possibilidade do enunciado em geral e que, portanto, só há enunciado se houver temporalidade, então, para que possamos provar isso, é necessário que interroguemos agora cada uma dessas condiçôes com vistas à compreensão de ser que lhes é pressuposta e, também, quanto aos seus supostos sentidos temporais. ${ }^{8}$

\footnotetext{
${ }^{8}$ Apesar de os temas "linguagem" e "temporalidade" serem bastante debatidos em Heidegger, não é vasta a literatura crítica que busca relacionar diretamente tais termos. Destacadamente, temos o livro de Takako Shikaya, Logos und Zeit (2004), o qual visa a examinar as interpretaçôes do jovem Heidegger
} 


\section{ANÁlise da TEMPORALIDADE DA PREDICAÇáo}

Já insistimos na questáo de que a primeira condiçáo de possibilidade da predicação consiste em que o "fazer ver" determinador que caracteriza o enunciado seja viabilizado a partir de uma compreensáo primária que entrega o ente previamente dado à possibilidade de sofrer uma determinação. $\mathrm{O}$ fato de o enunciado ser um mostrar determinador, quer dizer, um mostrar algo enquanto algo, não é nenhuma novidade. Em De Interpretatione, Aristóteles (Int. 17a) afirma que "Todo dizer em geral é significativo, [...] mas nem todo [dizer em geral] é apofântico (faz ver), mas [só] aquele em que está previamente presente o ser verdadeiro ou ser falso". ${ }^{9}$ Além disso, ele assevera

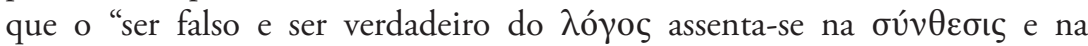

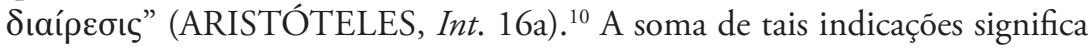

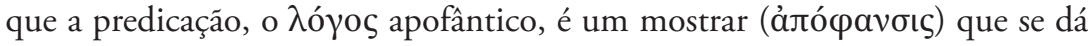
em função de uma estrutura de síntese e separação de algo com algo outro, na afirmação ou negação de algo enquanto algo (ARISTÓTELES, 1976, p. 127-142). Por essa razão, a predicação deve sempre assumir a forma "S é P". Por sua vez, para que algo como a determinaçáo seja possível - e, portanto, a própria predicação -, é necessário que isso de que o enunciado trata já se tenha feito acessível, já tenha sido compreendido previamente, por exemplo, no "para-que" de sua utilidade.

acerca da teoria da predicação aristotélica. A conclusão a que Takako chegará em sua obra não é distinta da nossa, a saber, que o logos predicativo se fundamenta na temporalidade da presentificaçáo (p. 57-65). M. Steinmann, em Die Offenheit des Sinns (2008, p. 286 a 293), também alude ao caráter do presente [Gegenwart] na linguagem e no tempo. Há, ainda, um artigo de J.J. Kockelmans, Zeit und Sprache im Ereignis (1988), que, como o próprio título bem resume, procura relacionar o tempo e a linguagem com o sentido de Ereignis. Notoriamente, temos ainda o livro organizado por Enno Hudolph e Heinz Wismann, Sagen, was der Zeit ist (1992), que busca, assim como o presente artigo, apresentar análises da temporalidade da linguagem. Destacam-se, nessa coleção, os textos de Franco Volpi, Die Ontologisierung der Sprache (入óyos) beim frühen Heidegger im Rückgriff auf Aristoteles, e G. Figal, Die Intuition einer radikal historischen Philosophie Sprache und Zeit in der Philosophie Martin Heideggers. Ademais, G. Figal, no livro Gegenständlichkeit (2006), irá elaborar, de modo bastante apropriativo, a relação entre liberdade, linguagem e tempo como três dimensões que caracterizam o mundo enquanto "espaço hemenêutico". Por fim, em temática paralela, temos o livro de Verena Rauen, Die Zeitlichkeit des Verzeihens (2015), o qual traz o "perdão" como uma simbiose de tempo e linguagem. Embora Takako e Steinmann tenham observado o fundamento da predicaçáo na presentificaçáo, eles parecem nấo ter enxergado o fato de que tal fundamento pode nos revelar um critério de análise temporal da linguagem que permite verificar a possibilidade de um modo discurso poder ou nấo tratar das palavras fundamentais da filosofia.

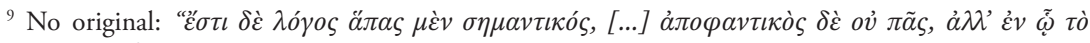

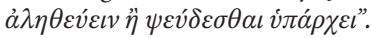

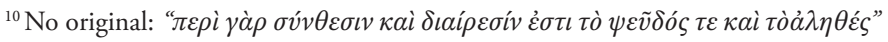


O que se quer dizer com isso é que só podemos predicar sobre o livro, se ele já se abriu antes no seu "para ler". Todo enunciado sobre algo requer que esse algo já esteja de alguma maneira aberta para o homem, já tenha comparecido na ocupação (Besorgen) do homem para com os entes. O enunciado jamais confere significado a "algo" que estava previamente "vazio de significação". Os entes não "ganham" significação pela primeira vez com o meu enunciar. Não há ente algum sem sentido, despido de qualquer significação e que só depois, por meio de qualquer tipo de concatenação intelectual, venha, então, a vestir-se de algum significado. Tudo o que aparece já sempre aparece compreendido e interpretado enquanto tal ou qual ente, seja no seu "para ler", "para escrever", "para se divertir”, enfim. Sempre nos movemos, por conseguinte, já de entrada nessa compreensão prévia e, como tal, antepredicativa. ${ }^{11}$ Quanto a isso, Heidegger (1976, p. 143-152) dirá que tal compreensão primária, na medida em que possibilita pela primeira vez que algo venha ao encontro enquanto algo, tem a estrutura de um "enquanto" ( $\mathrm{Als}$ Struktur) hermenêutico. ${ }^{12}$

\footnotetext{
${ }^{11} \mathrm{O}$ que está destacado com isso é que, de modo antepredicativo, a compreensão prévia já nos lança em uma visão compreensora que interpreta e destaca o ente em seu "enquanto-tal". De modo mais preciso, poder-se-ia dizer que, quando pegamos um livro na estante e o abrimos sobre a mesa para lê-lo, não precisamos, para isso, lançar mão de qualquer enunciado, pois, antes mesmo de qualquer enunciado "acerca de...", o livro, a estante, a mesa já se fizeram acessíveis numa compreensão interpretante. Aliás, só porque essa compreensão primária já explicitou o ente em seu "enquanto" [als] é que se poderá pronunciar um enunciado temático a respeito de tal ente. Assim, tal articulação da compreensão primária que faz com que o ente se torne explicitamente acessível em seu "enquanto" não só é prévia como é possibilitadora da estrutura do enunciado que lhe enseja ser um enunciado acerca de... Isso diz no fim que todo falar sobre algo trata de algo que já se fez aberto, que já se fez compreendido e interpretado enquanto algo. Só posso falar de mesa, estante, livro etc., se antes eles já se abriram nesse horizonte no qual são explicitados em seu "para-que", o que implica que é a partir dessa estrutura do "para-que" que o ente chega a ser desvelado. Não é por meio de uma concatenação ou de qualquer outra construção intelectual acerca de algo que eu venho a conceber algo enquanto algo. O "paraque" é justamente aquilo que já está dado de início e que desvela o ente, ou, em outras palavras, todo perceber é perceber algo enquanto algo; todo haver, toda lida, todo ter com algo é sempre e a cada vez um haver, lidar e ter com algo enquanto algo. Todo aparecer de algo é sempre um aparecimento de algo enquanto algo. Sobre isso, assinala Heidegger: "Quadro negro - incompreensível - enquanto tal não está presente à vista - oculto, se não compreendido como para escrever. Porta - do mesmo modo - para sair e entrar!” (HEIDEGGER, 1976, p. 144, nota 8, tradução nossa).
}

12 "[O 'enquanto'] é uma estrutura que, enquanto tal, faz parte da compreensão; compreensão, que deve ser aqui entendida como um modo básico de ser da nossa existência [do Dasein]. [...] O "enquanto" tem a funçấo de descobrir algo - a partir de algo - enquanto algo, isto é, enquanto o compreendido na compreensão. $\mathrm{O}$ enquanto é a estrutura da compreensão em geral e compreensão significa: 'E $\rho \mu \eta v \varepsilon i ́ a$. Compreender é o comportamento básico da existência. A estrutura do "enquanto" é, portanto, a estrutura básica hermenêutica do ser dos entes chamamos de existência [Dasein] (vida humana). Esta estrutura básica hermenêutica é apreendida relativamente e originalmente de forma simples no ter-que-fazer-se [no tratar, no lidar] com - que o mostrou. Esta unidade da estrutura básica, que se 
Visto que semelhante estrutura expóe o ente em sua compreensão primária, pode-se sustentar que ela é um comportamento do homem no qual já sempre nos movemos, no qual já sempre vivemos. Ela não é uma estrutura tematizante, teorizante do ente, ao contrário, ela é a estrutura na qual os entes já estão imediatamente dispostos. Ela abre este ou aquele ente enquanto tal, no contexto do "para-que", que já está de início articulado na medida em que me movo em uma determinada ocupação (Besorgen $)^{13}$ para com este ou aquele ente.

Mas qual é o sentido temporal dessa condição de possibilidade do enunciado? Ora, se essa estrutura "enquanto" é um comportamento que corresponde à compreensão prévia que desvela o "para-que" determinado de um ente na ocupação (Besorgen), o seu fundamento temporal é o mesmo que fundamenta a ocupação (Besorgen). Somente quando, na ocupação, expectamos o "para-que" da utilizaçáo do utensílio e retemos esse "para-que" como aquilo "com-o-que" se visa no uso é que o utensílio se mostra em sua condição respectiva (Bewandtnis) $)^{14}$ e pode, assim, presentificar-se enquanto

expressa com o "enquanto", não pode ser resolvido em partes, mas apenas pode-se interpretar como um todo originário em sua totalidade” (HEIDEGGER, 1976, p. 151, nota 6, tradução nossa).

${ }^{13}$ Heidegger cunha esse termo em Ser e Tempo para designar a lida do homem com as coisas. Todo "produzir alguma coisa, cultivar e cuidar, usar, abandonar e deixar perder-se, empreender, impor, pesquisar, interrogar, contemplar, discutir, determinar..." (2002, p. 95, tradução de Marcia Schuback), todos esses modos de o homem se relacionar com as coisas têm o modo de ser da ocupaçáo (Besorgen). Essa lida, por sua vez, é orientada não por um conhecimento teórico ou por uma contemplação constatadora de propriedades, mas por aquilo que Heidegger chama de "circunvisão" (Umsicht), que não é mais do que um "ter em vista o que estar dado em volta”. Esse "ter em vista”, em sua visão de conjunto, abarca de modo usual, isto é, não teórico, "o material, o usuário, o uso, a obra, em todas as suas ordens" (Notas Explicativas n. 18. In: HEIDEGGER, 2002, p. 314) e dirige o manejo com o ente que está dado a mão. Poderíamos dizer que "circuvisão" (Umsicht) é o evidente na ocupação com o ente no mundo. Ademais, que a ocupação seja um "modo de ser" deve significar que ela é um termo ontológico que indica uma determinada possibilidade de ser. Essa possibilidade da ocupação é típica do homem e diz respeito ao modo como ele é em relação às coisas. Contudo, na ocupação, isto é, na lida com o ente, nós não lidamos primeiramente com o ente que tem o modo de ser do que está aí simplesmente presente, da presentidade (Vorhandenheit), mas sim com aquilo que é utensílio, instrumento, com o ente que tem o modo de ser do manual (Zuhandenheit). Cf. também Heidegger (2004, p. 158-162).

${ }^{14} \mathrm{O}$ termo "Bewandtnis" (arranjo, condição respectiva) não se refere a outra coisa senão ao modo de ser do ente que se encontra à mão, isto é, do utensílio, do manual. "Bewandtnis" é, portanto, a manualidade (Zuhandenhei) que indica que o utensílio já se encontra sempre em uma condição respectiva com os outros entes, o que significa que, segundo seu modo de ser, um utensílio jamais pode ser entendido de modo isolado ou particular. Ele só vem à tona por carregar em seu modo de ser essa condição respectiva (Bewandtnis) com os outros entes. Poderíamos também traduzir "Bewandtnis" por "arranjo". Isso fica claro em algumas expressōes própria do alemão como "es sich bewenden lassen" - que significa "deixar (algo) se virar sozinho", "deixar algo ser como é", "deixar algo se arranjar" - e "es hat seine eigene Bewandtnis", que diz que "(algo) tem sua condiçấo própria”, "seu próprio arranjo”. A tradução de "Bewandtnis" por "conformidade", tal aparece muitas vezes em português, pode trazer alguns prejuízos, pois pode levar a entender, especialmente em "bewenden lassen", que se trataria de 
tal ou qual utensílio. A primeira condição de possibilidade da predicação, enquanto a compreensão primária que deve fazer acessível pela primeira vez o ente que há de ser tratado no enunciado, possibilita-se, portanto, a partir da estrutura ekstática da temporalidade da ocupação (Besorgen). Essa condição é ela mesma uma abertura que se funda no "para-fora" da temporalidade mediana e ocupada (gewartigen - behalten - gegenwärtigen), ou seja, ela mesma é um "antecipar-se a si estando já em um mundo"15 em que o homem está lançado em meio ao que comparece no mundo enquanto tal ou qual ente à mão (Zuhanden) da ocupação.

Contudo, visto que essa compreensão prévia se volta sobre o ente que já foi aberto por ela, a fim de tomá-lo tematicamente em um enunciado, há uma modificação da sua estrutura "enquanto", a qual passa a abrir o ente, náo mais no modo da instrumentalidade (Zuhandenheit), mas no modo da presentidade (Vorhandenheit). A transformação opera-se na própria possibilidade de tal "fazer ver" se tornar um "fazer ver determinador". Aqui podemos perceber o entrelaçamento entre a compreensão primária e a presentidade constante. ${ }^{16}$ $\mathrm{O}$ que se mostra é que a presentidade constante náo está pressuposta na compreensão primária, para que esta possa existir, ou seja, a presentidade não é uma condição de possibilidade da compreensão primária, todavia, está pressuposta na compreensão primária a possibilidade de ela desvelar o ente em sua presentidade. O poder deixar-se modificar enquanto um desvelamento que visa à presentidade é inerente à compreensão primária, e é nesse modificar que vem à tona a segunda condição de possibilidade da predicação em geral. Mas, como se dá essa modificação na estrutura "enquanto", que passa de um abrir da compreensão primária para um mostrar determinativo?

Ressaltamos que o homem jáse move sempre em uma compreensibilidade daquilo que o circunda, e que essa compreensibilidade primeira tem uma estrutura "enquanto", a qual consiste em um comportamento desvelador do homem que descobre os entes enquanto tais ou quais. Nessa perspectiva,

uma ação do homem. Esse não é o caso. Como já insistido, "Bewandtnis" designa o modo de ser do ente que está à mão, do utensílio em sua relação com os demais utensílios. Entretanto, quando o "remetimento" (Verweisung) finalmente alcança e toca a existência do Dasein, o termo que Heidegger (2006, \$18) passa a utilizar é "significância” (Bedeutsamheit).

15 "Sich-vor-weg-im-schon-sein-in-einer-Welt" (HEIDEGGER, 2006, p. 192). (Cf. HEIDEGGER, 2003, p. 214). Com essa "expressão", Heidegger faz referência aos três momentos estruturais constitutivos da temporalidade e ressalta, também, seu caráter unitário.

16 "Presentidade constante" (ständige Anwesenheit) é a expressão que Heidegger emprega toda vez que quer se referir ao modo de ser daquilo que se encontra presente à vista, isto é, do ente que tem o modo de ser da Vorhandenheit. Vide Cruz (2018). 
podemos argumentar que somente porque o homem já sempre desvelou previamente os entes em sua trama significativa é que ele pode manifestar tais significados em palavras, na linguagem. Isso significa que a linguagem, a fala, a emissão verbal só se faz possível em dependência de seu fundamento, que é a essa compreensão prévia. No entanto, asseverar só isso não supre um esclarecimento quanto à afirmação de que essa função hermenêutica da estrutura "enquanto" é o fundamento do enunciado. Com essa afirmação, está dito apenas que a trama de significados que o enunciado carrega em sua unidade só se faz possível sobre o fundamento da significação em geral, enquanto estrutura fundamental da apropriação da compreensão e do acesso temático do homem ao ente.

Entretanto, para que realmente possamos explicar melhor como essa estrutura "enquanto" hermenêutica é o fundamento do enunciado em sua mostração, temos de seguir, com Heidegger, uma análise da estrutura da mostração do enunciado mesmo.

Heidegger observa que, no enunciado, aquilo que, antes, na estrutura "enquanto" hermenêutica se compreendia enquanto tal ou qual utensílio, passa agora a ser o "acerca-de-que” desse enunciado. Para Heidegger, há aí uma modificação no caráter mostrativo da estrutura "enquanto", a qual abria o ente desde o seu "para-que" em uma compreensão primária e que agora passa, no enunciar, a mostrar esse ente previamente dado enquanto um isto "acerca-deque" se fala. O mostrar do enunciado tem, então, a pretensão de fazer visível, isto é, presente à vista (Vorhanden) aquilo que, na compreensão, já foi antes compreendido e desvelado (enquanto Zuhanden) (HEIDEGGER, 1976, p. 154). O enunciado, assim, tem seu sentido também em um descobrir, no qual “o já descoberto há de seguir descobrindo-se” (HEIDEGGER, 1976, p. 155).

De imediato, tal transformação - levada a cabo na tematização enunciativa daquilo que se compreendia enquanto isso ou aquilo, isto é, aquilo com que (Womit) eu já estou sempre lidando, e que agora se converte num "acerca-de-que" (Worüber) do enunciado - não muda a compreensibilidade mesma desse "com-que" da compreensão primária. Não é só porque eu enuncio simplesmente que o "livro é velho" que hei de perder por absoluto a compreensão primária que aponta o "para ler" do livro. Em tal enunciado, ainda compreendo que o livro é "para ler". O que ocorre é que, no enunciado, esse "para ler" se torna agora tão somente uma característica, isto é, uma qualidade presente no livro. $\mathrm{Na}$ transformação operada pela predicação que torna o ente previamente compreendido em um "acerca-de-que", a própria 
predicação só irá conseguir mostrar esse "acerca-de-que" a partir das qualidades que se fizerem presentes (Vorhandenen) nele mesmo.

Tal é o motivo pelo qual, segundo Heidegger, o enunciado é pensado

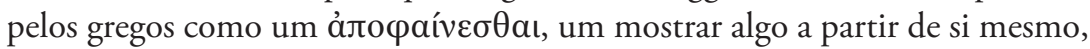
pois ele só consegue predicar sobre aquilo que se faz presente (Vorhanden) no "acerca-de-que" se fala. Pode-se assinalar, em outras palavras, que o mostrar, o fazer ver do enunciado, se concentra naquilo mesmo sobre o qual ele quer falar. Esse concentrar se dá sobre aquilo mesmo de que o enunciado trata, de sorte que o enunciado, ao tentar dizer algo enquanto algo, traz junto somente aquilo que está presente com o "acerca-de-quê". Percebe-se facilmente isso, por exemplo, no enunciado "este livro é velho". Aqui, o enunciado só pode falar do livro trazendo junto apenas o que está presente no livro, por exemplo, a característica de velho. Velho é o que "está junto", presente no livro. O enunciado, por conseguinte, ao trazer junto daquilo do que se fala (o livro) o que está nele presente (velho), acaba por determinar isso mesmo sobre o que se fala (o livro). No enunciado, o "isto acerca-de-que se fala" (S) é mostrado/ determinado a partir de (é) algo que lhe é presente (P). A determinação é, dessa forma, a característica fundamental do enunciado. Tal mostrar, determinar, por também mostrar algo enquanto algo, carrega da mesma forma uma estrutura "enquanto", porém, diferente da estrutura "enquanto" da compreensão primária. Heidegger (1976, p. 153 a 161) chamou essa estrutura de "enquanto" apofântico.

Ao contrário da estrutura "enquanto" hermenêutica que compreende algo enquanto algo desde o "para-que", a estrutura "enquanto" apofântica do enunciado só compreende algo enquanto algo a partir do que se faz presente no ente já entendido como um "acerca-se-que". ${ }^{17}$ Tal estrutura "enquanto" do enunciado é, assim, uma remarcação, uma restrição, limitação da estrutura "enquanto" da compreensão primária. Em razão disso, Heidegger (1976, p. 159) pontua: "O determinar enunciativo nunca é um descobrir primário, o determinar enunciativo nunca determina uma relação primária e original com o ente". ${ }^{18}$ Ele nunca há de abrir o ente com o qual ele lida a partir de seu "para-

\footnotetext{
${ }^{17}$ Heidegger (1976, p. 158) definiu o enquanto apofântico como "trazer junto [Beibringen] algo presente [Vorhandenen] mostrando-o em seu estar presente deste ou daquele modo".

${ }^{18}$ Por nunca determinar "uma relação primária e original com o ente", Heidegger também enfatiza que a predicação "jamais pode chegar a ser fio condutor para a pergunta acerca do que é o ente" (1976, p. 159, tradução nossa). Isto é, jamais se poderá esperar alcançar a resposta acerca do que é o ente, pronunciando meros enunciados sobre esse ente, atribuindo-lhe propriedades que lhe sejam presentes, acreditando que, assim, com o conjunto desses enunciados, se estaria apreendendo seu sentido último.
} 
que"; ao contrário, ele será sempre um mostrar o ente "acerca-de-que" se fala como um ente presente aí à vista (Vorhanden) que há de ser determinado pelo predicado com tais ou quais qualidades. Por isso, a presentidade constante é pressuposta no mostrar determinativo.

Porém, como o que foi destacado nos ajuda a responder a pergunta pelo sentido temporal da segunda condição de possibilidade da predicação?

Ora, uma vez que o enunciado é um mostrar determinador que afirma ou nega algo enquanto algo, podemos dizer que. nesse mostrar determinador. ele faz ver "aquilo-de-que" se fala como algo presente aí à vista em um agora. Contudo, tal "agora" não é tematicamente concebido no próprio enunciado, não é algo presente (Vorhanden) no agora. O agora permanece de modo atemático, oculto ao próprio enunciado. Ele só se tornará algo presente (Vohanden), se ele mesmo vier a se tornar tema do enunciado, ou seja, um "acerca-de-que" o enunciado fala. Embora o agora não seja a princípio algo presente à vista, é somente por meio do agora que algo presente à vista pode vir ao encontro, pois todo algo presente aí à vista é presente aí à vista em um agora. ${ }^{19}$ Que algo esteja aí presente à vista em um agora significa que $o$ agora deixa que algo saia ao encontro, que ele está à espera de algo. Que o agora seja um deixar que algo saia ao encontro significa que o agora em jogo no enunciado se expressa no presente (Gegenwart) ou, dito de modo mais adequando, que "o agora é presente (Gegenwart)" (HEIDEGGER, 1976, p. 401).

$\mathrm{Na}$ análise que Heidegger faz das ekstases da temporalidade, verificouse que o presente (Gegenwart) é uma ekstase que diz respeito à abertura do homem, é um deixar sair algo ao encontro. A partir da ekstase do presente (Gegenwart) é que o agora encontra o seu poder de presentificar. O "fazerpresente" (gegenwärtigen) em jogo nessa ekstase é, portanto, a "condição de possibilidade do agora” (HEIDEGGER, 1976, p. 401) ${ }^{20}$ e o agora, pressuposto

\footnotetext{
19 "Apenas tal ente, que tem o caráter do estar aí presente [Vorhandenseins], tem em si mesmo o seu sentido de ser para a possibilidade da sucessão (da sequência) e do atravessamento por um agora [Jet$z t$. Dizemos também que o ente cai no tempo ou, mais exatamente, que cai a cada vez em um agora. Assim, dito de modo inverso, se algo está determinado temporalmente nesse sentido, entáo significa que esse algo tem o modo de ser do que está aí presente [Vorhandenen]" (HEIDEGGER, 1976, p. 244, tradução nossa). O "agora" só é possível a partir de um dispor-se frente a algo que se apresenta e que se faz manifesto à vista. Tal comportamento é o que Heidegger chama de "presentificar", "presentificação" (Gegenwärtigen) de algo.

${ }^{20}$ Acrescenta Heidegger (1976, p. 401): "Das Gegenwärtigen ist allererst Bedingung der Möglichkeit dafür, daß so etwas wie "Jetzt" als jetzt das, jetzt dieses ausdrücklich werden kann" (A presentificação é, antes de tudo, condição de possibilidade para que algo como "agora" possa se fazer expresso enquanto "agora isto", "agora este").
} 
no enunciado enquanto um deixar sair ao encontro, é, por sua vez, o que possibilita que no enunciado um ente aí presente à vista (Vorhanden) possa se fazer presente. É o agora não temático pressuposto no enunciado que presentifica no modo da Vorhandenheit, isto é, que deixa algo vir ao encontro como algo presente em um agora.

Podemos sustentar, portanto, que, na medida em que o enunciado faz ver "aquilo-de-que" se fala como algo presente aí à vista em um agora, o mostrar determinador da predicação tem o sentido temporal de ser uma presentificação, de ser um "fazer-presente" algo aí à vista em um agora. Será em razão do que foi pontuado que Heidegger ressalta que o modo de ser do ente presente à vista em um agora (Anwesenheit) só se faz possível a partir do presente (Gegenwart) (Anwesenheit aus der Gegenwart). Sobre semelhante tema, Heidegger (1976, p. 414-415, grifos e tradução nossos) esclarece:

Enunciar: Deixar-ver de algo enquanto algo interpelando é uma possibilidade determinada da pura presentificação - o deixar-ser-presente do ente, enquanto o descobrir da presença de um ente presente aí à vista; é

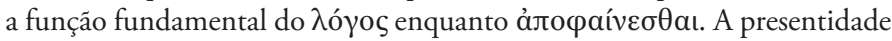
do ente presente aí à vista, que apenas é desvelado em um presente, não diz, porém, nada diferente do que o ser do ente. Cada descobrimento, isto é, cada enunciar presentificante diz, por isso, "è". [...] O "ê" [...] é o indício da função fundamental do enunciado, de sua presentificação enquanto uma pura presentificaçấo, puro deixar-ver da presentidade do ente, ou o ente em sua presentidade. $\mathrm{O}$ enunciado expressado guarda em si o descobrimento do ente. Mas guardar um descobrimento náo diz nada distinto do que poder-presentificar-a-cada-momento - descobrimento é, portanto, um presente possível iminente - do ente interpelado em seu ser e em seu ser assim. Descobrimento ou verdade do enunciado que se refere ao mundo significa presente. Mas ser significa presentidade, isto é, o sentido do ser é concebido desde o presente, em que só é possível algo como presentidade. ${ }^{21}$

\footnotetext{
${ }^{21}$ No original: "Aussagen: ansprechendes Sehenlassen von etwas als etwas ist eine bestimmte Möglichkeit des reinen Gegenwärtigens - das Anwesendseinlassen des Seienden, also das Entdecken der Anwesenheit

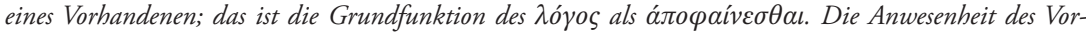
handenen, die nur entdeckbar ist in einer Gegenwart, besagt aber nichts anderes als das Sein des Seienden. Jedes entdeckende, d. h. gegenwärtigende Aussagen sagt daher "ist". [...]. Das Ist [...] ist der Index der Grundfunktion der Aussage, ihres Gegenwärtigens als eines reinen Gegenwärtigens, puren Sehenlassens der Anwesenheit des Seienden bzw. des Seienden in seiner Anwesenheit". Die ausgesprochene Aussage verwahrt in sich die Entdecktheit des Seienden. Verwahren einer Entdecktheit aber besagt nichts anderes als Jederzeitgegenwärtigenkönnen - Entdecktheit ist demnach eine ausgezeichnete mögliche Gegenwart - des angesprochenen Seienden in seinem Sein und Sosein. Entdecktheit bzw. Wahrheit der weltbezogenen Aussage besagt Gegenwart. Sein aber besagt Anwesenheit, d. h. der Sinn von Sein ist aus Gegenwart begriffen, darin allein so etwas möglich ist wie Anwesenheit".
} 
Tudo o que foi exposto até aqui indica como a presentidade está pressuposta nas duas primeiras condiçóes de possibilidade da predicação e quais são seus respectivos sentidos temporais. Contudo, tudo o que foi expresso está pensado somente a partir da perspectiva do comportamento desvelador do homem e, em especial, do mostrar determinativo. Precisamos, então, expor também o caráter temporal do próprio ente que vem ao encontro em tal mostrar.

Como já se sabe, a terceira condição de possibilidade do enunciado diz respeito a uma condiçấo especifica do ente na qual ele deve se deixar determinar. "Deixar-se determinar" também significa "poder ser dito por meio de algo outro", mesmo que esse algo outro pertença necessariamente àquilo que é predicado. Podemos enunciar, por exemplo, "a mesa é vermelha" ou "a mesa é extensa". No primeiro caso, o "ser vermelho" é uma qualidade acidental na mesa, enquanto, no segundo caso, o "ser extenso" é uma qualidade necessária à mesa. No entanto, em ambos os casos, "ser vermelho" ou "ser extenso" não é o mesmo que "ser mesa”. Isso quer dizer que a mesa está se deixando dizer por algo outro que não é ela mesma. O "algo outro" é uma qualidade, uma propriedade que, embora pertença à mesa, não é o mesmo que a mesa. $\mathrm{O}$ enunciado, por isso, exige que "o ente de que se fala" se deixe mostrar por meio de suas propriedades. "Que o ente passe a se mostrar por meio de propriedades" significa que o ente que vinha à tona, na ocupação circundante, passa a se tornar um "núcleo de propriedades". Conforme já insistido, a mesa deixa de ser um utensílio, isto é, é "suspensa" de seu contexto utensiliar, e passa a vir à tona enquanto um "acerca de que se fala" ao qual posso atribuir um predicado. Há aí uma mudança significativa no modo de ser do ente ${ }^{22}$, o qual passa agora a assumir o caráter da presentidade (Vorhandenheit).

Não me é dada de modo algum a possibilidade de pronunciar um enunciado acerca de algo que está no mundo sem que esse algo assuma o caráter de algo que está aí presente enquanto núcleo de propriedades (Anwesenheit), devido à estrutura determinadora do enunciado que faz ver o ente enquanto "isto" ou "aquilo" outro. Ser "isto" ou "aquilo" significa ser "algo" aí presente

${ }^{22}$ Quando Heidegger (1976, p. 158) definiu a estrutura enquanto apofântica como um "trazer junto [Beibringen] algo presente [Vorhandenen], mostrando-o em seu estar presente deste ou daquele modo", ele também está dizendo que essa estrutura acarreta um ocultamento do ente do qual o enunciado fala. A razão disso se dá porque, quando eu enuncio, por exemplo, "o livro é verde", eu transformo, em tal tematização, o que era mero instrumento em uma mera coisa. Tal determinaçáo do enunciado força uma modificação do autêntico caráter de ser do que foi descoberto na compreensão primária - o livro em uma mera coisa presente [Vorhanden], dotada de propriedades que lhe são atribuídas no enunciado. 
(Vorhanden). Assim, a presentidade (Vorhandenheit) é igualmente pressuposta na terceira condição de possibilidade do enunciado, ao contrário do que ocorre na lida cotidiana. Quando eu me apoio na mesa, ao ler ou ao escrever, a mesa nunca é um mero "isto" ou "aquilo", mas está antes totalmente entregue no "para-que" de sua condição respectiva (Bewandtnis).

Entretanto, onde reside o caráter temporal da terceira condição de possibilidade do enunciado? Presentidade - e, portanto, também, o ente que tem esse modo de ser - só pode vir à tona em um presente (Anwesenheit aus der Gegenwart). O presente (Gegenwart) enquanto uma ekstase da temporalidade é um comportamento desvelador em que se funda o "deixar comparecer" (Begegnenlassen) do ente que "está aî" (Vorhanden), possibilitando-lhe estar presente (anwesend) enquanto "isto" ou "aquilo". Lembremos que Heidegger (2012a, p. 387) afirma que essa relação entre Vorhanden e Gegenwart se dá, na medida em que o homem "[...] se comporta de maneira presentificante [gegenwärtigend] em relação a algo presente à vista [Vorhandenen] e mantém esse ente como algo presente [Anwesendes] em seu presente [Gegenwart]". É a ekstase do presente que, na presentificação (Gegenwärtigen), permite o manter o ente como algo presente (Anwesendes). A terceira condição de possibilidade do enunciado tem o seu caráter temporal demonstrado, na medida em que o ente em jogo no enunciado precisa poder deixar-se comparecer enquanto algo presente (Anwesendes) desde a presentifição (Gegenwärtigen) que se opera no presente (Gegenwart).

Tal conclusão, por sua vez, representa uma grave consequência ao enunciado, quando ele pretender tratar daquilo que não tem o modo de ser da Vorhandenheit, por exemplo, o ser ou o próprio tempo. Aliás, o tempo não só não possui o modo de ser da Vorhandenheit como, aliás, ele não possui modo de ser algum, porque ele mesmo náo é ente algum. No entanto, o tempo, quando é tematizado pelo enunciado, precisa deixar-se comparecer como um ente presente à vista (Vorhanden), isto é, como algo que está presente aí no "tempo". Esse "algo" em que o tempo se transforma é o "agora" de uma sucessão linear, o tempo que pode ser medido ${ }^{23}$ e vai passando. Tal "que vai passando" significa justamente que o "agora” está aí no tempo, ou seja, que ele é algo presente no tempo. Segundo Heidegger (2012b, p. 146ss), esse é o modo como a tradição filosófica, de Aristóteles até Hegel, compreendeu e interpretou o que é o tempo.

\footnotetext{
${ }^{23}$ Ser "medido" é uma possibilidade dos entes e não do tempo, em seu sentido mais próprio. Somente quando compreendemos o tempo como "algo", como um ente, é que eu posso, entấo, medi-lo.
} 
Visto que o tempo é determinado pelo enunciado e passa a ser interpretado como um Vorhanden, isto é, como algo que está aí presente no tempo, como um "agora", temos que o enunciado é incapaz de expor ele mesmo o tempo. Esta é a verdadeira fragilidade da predicação, do $\lambda$ ó ${ }_{0}$ s apofântico: age como um rei Midas que exige que aquilo que é tomado por ele venha a ter

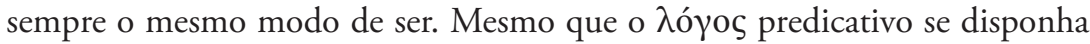
a falar acerca do $\operatorname{ser}^{24}$, do tempo, da existência, enfim, só conseguirá expô-los enquanto algo que está simplesmente presente aí à vista, isto é, enquanto um ente que tem o modo de ser da Vohandenheit. Isso ocorre mesmo quando predicamos enunciados como "a poesia de Homero é extemporânea" ou "a alma é eterna”. Quando dizemos algo como a "alma é eterna”, anunciamos que a alma que se encontra aí presente em um agora há de continuar eternamente aí presente e, assim, acabamos impondo à alma que ela assuma o caráter de um Vorhanden. Quando dizemos "a poesia de Homero é extemporânea", anunciamos que a obra de Homero que se encontra agora aí presente está para além do tempo determinado de sua concepção e está fora da concepção cronológica do tempo. No entanto, semelhante "não cronológico" em jogo nesse "extemporâneo" marca apenas uma oposição que só se faz compreensível a partir do tempo cronológico, do tempo do relógio, do tempo do agora. Impomos aí, talvez ainda mais marcadamente, o caráter de Vorhandenheit à obra de Homero como aquilo que, estando aí presente no tempo, resiste ao passar das épocas.

${ }^{24}$ É interessante frisarmos aqui sobre aquilo que Heidegger chama de "indicaçấo hermenêutica" (hermeneutischen Indikation). Na preleçáo Logik. Die Frage nach Der Wahrheit, Heidegger expóe uma distinção entre "enunciados sobre o mundo [weltliche Aussage]" e o que poderíamos chamar de "enunciados existenciais [Aussagen über Sein des Daseins]". Ao contrário do enunciado sobre o mundo - que expressa sempre algo presente à vista (Vorhanden) - o enunciado existencial trata do ser do Dasein e de todas as problemáticas da temporalidade, mas sem presentificar o seu conteúdo. Isso seria possível, destaca Heidegger, porque os enunciados existenciais teriam a função de apenas indicar a existência, ou melhor, a compreensibilidade das estruturas existenciais. Para Heidegger, os enunciados existenciais, na medida em que se voltam para a própria compreensão do Dasein, requerem um "reajuste" (Umstellung) da compreensão que tem em vistas a si mesma. Tal reajuste permite que o enunciado existencial se volte sobre a compreensão de modo indicativo e não na tendência de uma presentificaçáo. Porém, Heidegger também nos lembra de que nos movemos, na maioria das vezes, na tendência de tomarmos esses enunciados existenciais como enunciados mundanos, o que faz, por exemplo, com que o tempo se faça "inacessível em sua própria temporalidade". A interpretação aristotélica do tempo é, conforme Heidegger, um exemplo dessa tendência. Mas não só isso. Heidegger ainda aponta: "Com os gregos, tanto com Platáo quanto com Aristóteles, a diferença entre enunciado categorial e enunciado sobre algo presente aí à vista no mundo fica encoberta e, por isso, todo enunciado era compreendido diretamente enquanto enunciado sobre o mundo, o que levou que o ser mesmo, táo logo se pudesse ver, fosse concebido enquanto ente" (HEIDEGGER, 1976, p. 410, nota 8, tradução nossa). Sobre as indicaçóes hermenêuticas, vide o acurado trabalho de R. R. dos Reis (2000, 2011). 
Chegamos aqui a um momento decisivo de nossa investigação. Com a exposição do sentido temporal específico de cada uma das condições de possibilidade da predicação, foi possível perceber como elas estão ligadas entre si, na estrutura da temporalidade. Finalmente, ficou realçado, ao expor o sentido temporal do enunciado como uma presentificação (Gegenwäntigen) que mostra algo presente (Anwesenheit) a partir do presente (Gegenwart), que o tempo é o elemento vinculador das condiçôes de possibilidade da predicação e que só pode haver algo assim como o enunciado, na medida em que há temporalidade.

Também ficou expresso que o enunciado, por exigir que o ente por ele tratado assuma o modo de ser do Vorhandenheit, é incapaz de expor adequadamente tanto o próprio tempo quanto todas as outras palavras fundamentais. Tal incapacidade, a qual advém do modo como o enunciado se fundamenta na estrutura imprópria da temporalidade, impossibilita a predicação de tratar adequadamente das palavras fundamentais e, portanto, não constitui um caminho possível ao fazer filosófico.

A pergunta que surge naturalmente de tal conclusão é: será que há alguma possibilidade discursiva que enseje um acesso às palavras fundamentais? Somente uma análise específica do sentido temporal das múltiplas possibilidades discursivas pode esclarecer se há alguma capaz de pensar o tempo e as demais palavras fundamentais, sem "coisificá-las" e, consequentemente, sem determiná-las a partir daquilo que elas não são.

De fato, se concluímos que é por meio da análise temporal de cada uma das possibilidades discursivas que descobriremos se elas são, de fato, um discurso que possibilita um acesso genuíno às palavras fundamentais, já estamos admitindo que o tempo é o critério a ser observado na investigação dos limites da linguagem ou, melhor, que tal critério se funda na relação que uma determinada possibilidade discursiva guarda com a temporalidade.

\section{ConsideraçốES FINAIS}

Com o que foi visto até aqui, ficou indicado que o enunciado em geral assegura sua possibilidade na estrutura da temporalidade, na medida em que o mostrar determinativo da predicaçáo é uma presentificação. Mostrouse também que, em razão de o ente presente à vista (Vorhanden) só poder vir à tona em uma presentificação, o enunciado fundamenta-se na estrutura 
imprópria da temporalidade (expectação - retenção - presentificação). Por garantir sua possibilidade em função de tal estrutura imprópria, verificou-se que o enunciado é incapaz de expor o essencial das palavras fundamentais, sem transformar o que está em jogo nelas em um "acerca-de-que" presente aí à vista.

Ao tratarmos do enunciado em geral, antecipamos, contudo, que tanto essa possibilidade discursiva quanto toda a linguagem discursiva em geral se fundamentam na temporalidade, porque, como já enfatizado, somente a partir do momento que os entes já foram antecipadamente desvelados em uma trama significativa pela compreensão prévia do homem (enquanto hermenêutico) tais significaçôes podem se expressar em palavras, na linguagem discursiva (HEIDEGGER, 1976, p. 151-152). Significa que somente porque o homem se move enquanto tal, em um "antecipar que já sempre compreendeu", os entes podem comparecer previamente como tais ou quais entes e se deixarem apreender tematicamente. Com efeito, dizer que toda possibilidade discursiva se funda nesse "antecipar que já sempre compreendeu” é o mesmo que dizer que toda possibilidade discursiva encontra seu fundamento na estrutura da temporalidade. Mas o que ganhamos com tal afirmação? Ganhamos o decisivo na questão a propósito da possibilidade de um discurso dispor-se de modo adequado frente às palavras fundamentais. Desde o momento em que mostramos como a predicação encontra os fundamentos de suas condições de possibilidade na estrutura da temporalidade já ocupada, isto é, a partir dos modos impróprios das ekstases temporais (expectação - retenção presentificação $)^{25}$, surge, então, a possibilidade da colocação da questáo fulcral de nossa investigação, a saber, será que há alguma possibilidade discursiva que náo se fundamente nos modos impróprios das ekstases temporais ou, mesmo que se possibilite inicialmente, a partir deles, permita um salto para os modos próprios da temporalidade (adiantar-se - repetição - instante) ${ }^{26}$ ? Se conseguirmos mostrar como uma determinada possibilidade discursiva pode estar em consonância com os modos próprios da temporalidade, então nos estará dado que tal possibilidade é um modo de acesso genuíno às palavras fundamentais. $\mathrm{O}$ modo como uma determinada possibilidade discursiva se relaciona com a temporalidade deve ser, portanto, o critério a ser observado.

Com o que foi desenvolvido até aqui, cumprimos o objetivo derradeiro de nosso estudo, a saber, expor a novidade da elaboração de um critério

\footnotetext{
${ }^{25}$ Gewärtigen - Behalten - Gegenwärtigen.

${ }^{26}$ Vorlaufen - Wiederholung - Augenblink.
} 
temporal que fundamente a possibilidade do acesso de uma possibilidade discursiva às palavras fundamentais. Contudo, a realização plena do trabalho aqui elaborado só será plenamente satisfeito, quando empreendermos a verificação de como uma possibilidade discursiva específica pode, de fato, encontrar seu respaldo na estrutura própria da temporalidade (adiantar-se repetição - instante). O estabelecimento do tempo como critério de verificação para a possibilidade de um autêntico discurso filosófico constituiu, não obstante, uma tarefa preliminar necessária e decisiva.

CRUZ, E. L. Time as a criterion of verification of the possibility of philosophical discourse. Trans/form/ação, Marília, v. 43, n. 3, p. 167-186, Jul./Set., 2020.

\begin{abstract}
The main objective of the present study is to identify time as the criterion of verification of the possibility of a philosophical discourse, that is, of a discursive possibility to be able to speak adequately about the fundamental words. For this, it will be interesting to show how time is the linking element of the conditions of possibility of the statement in general and how it is based on the improper structure of temporality. Such prerogative is what makes the predication impossible to adequately treat any fundamental word. It must then be said that only a discursive possibility based on the structure of temporality can have adequate access to the fundamental words.
\end{abstract}

Keywords: Heidegger. Time. Predication. Philosophical discourse.

\title{
REFERÊNCIAS
}

CRUZ, Estevão L. A pré-história da significação de oủoía: Uma análise da interpretação heideggeriana de ousia enquanto presentidade (Anwesenheit). Archai: Journal on the origins of Western thought, n. 25, Brasília, 2019a.

CRUZ, Estevão L. A temporalidade como condição de possibilidade da compreensão do ser do ente simplesmente presente à vista (Vorhanden). Universitas Philosophica, 36(73), 147-186, $2019 \mathrm{~b}$.

FIGAL, Günter. Gegenständlichkeit. Tübigen: Mohr Siebeck, 2006.

HEIDEGGER, Martin. Logik. Die Frage nach Der Wahrheit (Gesamtausgabe Band 21). Frankfurt am Main: Vittorio Klostermann, 1976.

HEIDEGGER, Martin. Ser e Tempo. Parte I. Tradução de Marcia Sá Cavalcante Schubak. Petrópolis: Vozes, 2002. 
HEIDEGGER, Martin. Ser y Tiempo. Tradução de Jorge Eduardo Rivera. Madrid: Trotta, 2003.

HEIDEGGER, Martin. Ser e Tempo. Parte II. Tradução de Marcia Sá Cavalcante Schubak. Petrópolis: Vozes, 2004.

HEIDEGGER, Martin. Sein und Zeit. Tübingen: Max Niemeyer Verlag, 2006.

HEIDEGGER, Martin. Os Problemas fundamentais da fenomenologia. Tradução de Marco Antônio Casanova. Petrópolis: Vozes, 2012a.

HEIDEGGER, Martin. A essência da liberdade humana: introdução à filosofia. Tradução de Marco Antônio Casanova. Rio de Janeiro: Via Veritas, 2012b.

HUDOLPH, Enno; WISMANN, Heinz (ed.). Sagen, was der Zeit ist. Stuttgart: Metzler, 1992.

KOCKELMANS, Joseph J. Zeit Und Sprache Im Ereignis. Phänomenologische Forschungen. Hamburg, vol. 21, p. 51-81, 1988.

RAUEN, Verena. Die Zeitlichkeit des Verzeihens. Paderborn: Wilhelm Fink, 2015.

SHIKAYA, Takako. Logos und Zeit. Heideggers Auseinandesetzung mit Aristoteles und der Sprachgedanke. Würzburg: Königshausen \& Neumann, 2004.

STEINMANN, Michael. Die Offenheit des Sinns. Tübigen: Mohr Siebeck, 2008.

REIS, Robson R, dos. Modalidade existencial e indicação formal: elementos para um conceito existencial de moral. Natureza Humana, v. 2, p.273 - 300, 2000.

REIS, Robson R, dos. Aspectos do pensamento indicativo-formal: negação e justificação. Natureza Humana, v.13(1), p.117 - 133, 2011.

Recebido: 17/07/2018

Aceito: 23/02/2020 